\title{
Screening for serum biomarkers in patients with chronic hepatitis B with hepatitis B surface antigen seroclearance, following pegylated interferon alpha therapy
}

\author{
ZHELING WANG, XIAOFEI LI, CHANGHE SHI, MIN ZHANG, RU CHEN, WEI WU, QINGSHUN HOU, \\ WEI KE, TIANLI FAN, ZIRONG WEN, XINJIE HAO and NAIFANG QU
}

Qingdao Hospital for Infectious Diseases, Qingdao, Shandong 266033, P.R. China

Received February 4, 2014; Accepted August 6, 2014

DOI: $10.3892 / \mathrm{mmr} .2014 .2670$

\begin{abstract}
Chronic hepatitis B (CHB) is one of the most common infectious disease worldwide and a leading cause of death. Hepatitis B surface antigen (HBsAg) has previously been proven to be a steady biomarker that may be used to predict clinical outcomes. The amount of circulating HBsAg has been reported to reflect the number of infected hepatocytes. An advantage of pegylated interferon alpha (peg-IFN- $\alpha$ ) is that as a finite course of therapy, it can potentially lead to sustained disease remission in subsequent decades. HBsAg seroclearance can reportedly be achieved in some hepatitis $\mathrm{B}$ patients treated with peg-IFN- $\alpha$; this is a major advantage of IFN- $\alpha$, as compared with nucleoside analogue treatment. In the present study, a random phage display peptide library was used to screen for potential serum peptide biomarkers in predicting which patients with $\mathrm{CHB}$ would exhibit $\mathrm{HBsAg}$ seroclearance, following 48 weeks of peg-IFN- $\alpha$ therapy. A total of 30 patients with CHB who achieved HBsAg seroclearance following peg-IFN- $\alpha$ therapy and an additional 30 age-, gender-, hepatitis B e antigen ( $\mathrm{HBeAg}$ ) status- and hepatitis B virus genotype-matched patients with $\mathrm{CHB}$ without $\mathrm{HBsAg}$ seroclearance following peg-IFN- $\alpha$ therapy, were enrolled as a discovery cohort. In the discovery/screening phase, 17/20 of the randomly selected phage clones, exhibited a specific reaction with purified sera immunoglobulin $\mathrm{G}$ from the $\mathrm{HBsAg}$ clearance group, and 13/17 positive phage clones came from the same phage clone, with the inserted peptide sequence ETCRASCINESA (named IFNC1). In the validation phase, phage-ELISA results showed that the positive reaction rate of the IFNC1 peptide phage clone was $92.0 \%$ with the HBsAg seroclearance group $(n=50)$, which was significantly higher, as
\end{abstract}

Correspondence to: Dr Changhe Shi, Qingdao Infectious Diseases Hospital, 9 Fushun Road, Qingdao, Shandong 266033, P.R. China E-mail: sch43@126.com

Key words: chronic hepatitis B, pegylated interferon $\alpha$, hepatitis B surface antigen, phage display peptide library, biomarker, predictive validity compared with the randomly selected HBsAg non-clearance group $(12.0 \%, \mathrm{n}=50)$ and the healthy control group $(8.0 \%$, $\mathrm{n}=50$ ). In conclusion, the newly identified mimic peptide IFNC1 showed a high predictive validity HBsAg seroclearance in patients with $\mathrm{CHB}$, following peg-IFN- $\alpha$ therapy. Therefore IFNC1 may be a potential serum biomarker, which could be used to predict the treatment outcomes of peg-IFN- $\alpha$ therapy.

\section{Introduction}

Chronic hepatitis B (CHB) is one of the most common infectious diseases and leading causes of death, with $\sim 400$ million chronically infected individuals worldwide (1). Over the past three decades, progressively more patients have received treatment; initially with interferon alpha (IFN- $\alpha$ ), and recently with the advent of nucleoside analogues (2). IFN- $\alpha$ has restricted efficacy, as not all patients will exhibit a therapeutic response. However, in some hepatitis B e antigen ( $\mathrm{HBeAg}$ )-positive and -negative patients, the sustained suppression of viral replication and the seroclearance of hepatitis B surface antigen ( $\mathrm{HBsAg}$ ) may be attained (2).

Recombinant IFN- $\alpha$ is used clinically worldwide. However, the efficacy of the therapy is restricted by protein characteristics, including poor stability, a short half-life and immunogenicity. Recent advances in pegylation technology have resulted in the development of pegylated (peg) IFN- $\alpha$, which leads to a reduced clearance of IFN- $\alpha$, and therefore an increased circulatory time and sustained systemic exposure (2).

HBsAg was initially identified $>40$ years ago (3). The detection of HBsAg in the serum is the hallmark of hepatitis $B$ virus $(\mathrm{HBV})$ infection and remains the gold standard diagnostic marker of CHB. HBsAg has been proven to be a steady marker, that may be used to predict clinical outcomes (4). An advantage of peg-IFN- $\alpha$, as compared with nucleotide analogues, is that HBsAg seroclearance is observed in numerous patients undergoing peg-IFN- $\alpha$ treatment (2). It would therefore be beneficial to identify serum biomarkers that can predict which patients with CHB would have HBsAg seroclearance following peg-IFN- $\alpha$ therapy. The biomarkers would not only be potential treatment outcome predictors, 
but may also provide a new basis for evaluating the molecular mechanisms underlying $\mathrm{CHB}$ pathogenesis.

In 1985, Smith et al (5) established a method for displaying polypeptides on the surface of filamentous M13-derived bacteriophage (phage). This phage display technique was originally developed to map epitope-binding sites of antibodies, through the panning of random peptide-phage libraries on immobilized immunoglobulins. Since then, phage display has been used to determine polypeptide binding with a diverse range of basic biological, as well as technical and medical applications $(6,7)$. In the present study, a random phage display peptide library was used to screen for potential serum peptide biomarkers, in predicting which patients with $\mathrm{CHB}$ would exhibit $\mathrm{HBsAg}$ seroclearance following peg-IFN- $\alpha$ therapy.

\section{Materials and methods}

Subjects. Between January 2009 and February 2012, 1,120 Han Chinese patients with CHB, admitted to the Qingdao Infectious Diseases Hospital(Shangdong, China), were screened for HBsAg seroclearance following 48 weeks of peg-IFN- $\alpha$ therapy. A total of 30 patients with $\mathrm{CHB}$ who achieved HBsAg seroclearance following peg-IFN- $\alpha$ therapy and 30 age-, gender-, HBeAg status- and HBV genotype-matched patients with $\mathrm{CHB}$ without $\mathrm{HBs} \mathrm{Ag}$ seroclearance following peg-IFN- $\alpha$ therapy, were enrolled as the discovery cohort. A further 50 patients with $\mathrm{CHB}$ with $\mathrm{HBs}$ Ag seroclearance and 50 randomly selected patients with $\mathrm{CHB}$ without $\mathrm{HBsAg}$ seroclearance, following peg-IFN- $\alpha$ therapy, were enrolled as a validation cohort, to validate the potential serum peptide biomarkers identified in the discovery cohort. The baseline characteristics of the discovery and validation cohorts are listed in Tables I and II, respectively. A further 50 randomly selected healthy volunteers were enrolled as a healthy control group, in the validation phase. The recruited patients with CHB were diagnosed according to the Asia-Pacific consensus statement on the management of CHB (a 2008 update), by the Asian Pacific Association for the Study of the Liver (8).

All of the recruited patients with $\mathrm{CHB}$ underwent 48 weeks of peg-IFN- $\alpha$ therapy of 180-190 $\mu \mathrm{g} /$ week (Roche, Shanghai, China). All met the following criteria: HBV DNA load of $\geq 104$ copies $/ \mathrm{ml}$, elevated serum alanine aminotransferase (ALT) level 2-10 times the upper limit of normal and no immunotherapy or HBV vaccine treatment for 6 months prior to enrollment. The exclusion criteria for the recruited patients were as follows: Co-infection with hepatitis A (HAV), C (HCV), E (HEV) or human immunodeficiency (HIV) viruses; evidence of other etiological liver co-morbidities (e.g., alcohol-related, drug-related, or autoimmune diseases); serious concurrent medical illnesses (e.g., malignancy, severe cardiopulmonary disease, psychiatric disorders, uncontrolled diabetes mellitus, or hyper- or hypothyroidism); and pregnancy or nursing. Blood samples were collected from all of the screened $(n=1,120)$ patients with $\mathrm{CHB}$ at baseline, within 72 hours prior to peg-IFN- $\alpha$ therapy, at 48 weeks, the end of peg-IFN- $\alpha$ therapy, and finally at 80 weeks, 32 weeks post peg-IFN- $\alpha$ therapy. The patients with $\mathrm{CHB}$ who achieved consistent HBsAg loss, until 32 weeks post peg-IFN- $\alpha$ therapy, were included in the HBsAg seroclearance group in the discovery or validation cohorts. In the present study, only the baseline blood samples from the discovery and validation cohorts were used for the discovery/screening and validation tests with a random phage display peptide library. Blood samples were also collected from all of the healthy volunteers within 72 hours of enrollment $(n=50)$. The present study was approved by the Ethics Committee of Qingdao Infectious Diseases Hospital. Written informed consent was obtained from all of the participating subjects prior to the study.

Reagents. The phage display peptide library and the ER2738 Escherichia coli host strain were purchased from New England Biolabs Inc. (Ipswich, MA, USA). The QIAprep Spin M13 kit was purchased from Qiagen (Valencia, CA, USA). The serum ALT levels were measured using a fully automatic biochemical analyzer (AU2700; Olympus, Tokyo, Japan) with a 40 IU/1 upper limit of normal; HBV DNA was quantified by real-time polymerase chain reaction using an ABI PRISM 7000 thermocycler (Roche Molecular Systems Inc., Alameda, CA, USA) and a diagnostic kit (Daan Genetech, Guangzhou, China), with a linear range of $5.0 \times 10^{2}-1.0 \times 10^{9}$ copies $/ \mathrm{ml}$. HBsAg and HBeAg were detected using an auto-electrochemiluminescence technique (E170; Roche Diagnostics Ltd., Basel, Switzerland), with a normal detection limit of $<0.05 \mathrm{IU} / \mathrm{ml}$ for HBsAg and <1.0 S/CO for HBeAg.

Preparation of sera, biopanning and amplification of phages. All phage-related procedures in the present study were conducted as described by previous methods (9). Serum pools were obtained from the patients with $\mathrm{CHB}$, with or without HBsAg seroclearance following peg-IFN- $\alpha$ therapy, and from the healthy volunteers. Immunoglobulin $\mathrm{G}(\mathrm{IgG})$ was purified from the serum pools. To increase the screening specificity, microtiter wells were coated with purified sera IgG from the patients with $\mathrm{CHB}$ without HBsAg seroclearance, in order to absorb non-specific phages from the random phage peptide library. The unbound phages were then incubated with the sera IgG from patients with $\mathrm{CHB}$, with $\mathrm{HBs}$ Ag seroclearance, to screen for phage containing potential peptide biomarkers. Briefly, microtiter wells were incubated at $4^{\circ} \mathrm{C}$ overnight with $100 \mu \mathrm{l}$ of purified $\mathrm{IgG}(100 \mu \mathrm{g} / \mathrm{ml})$ from the patients with $\mathrm{CHB}$ without HBsAg seroclearance. The plates were blocked with $3 \%$ nonfat milk for 2 hours at $37^{\circ} \mathrm{C}$ and then washed five times with $0.05 \%$ Tween ${ }^{\circledR} 20$ in Tris-buffered saline. A $100 \mu$ l sample of the diluted random 12-peptide phage display library was added to the coated plates. Following a $1 \mathrm{~h}$ incubation at room temperature, the unbound phages were collected and added to a plate coated with sera IgG from the patients with $\mathrm{CHB}$ with HBsAg seroclearance (100 $\mu \mathrm{l} /$ well). Following a further $1 \mathrm{~h}$ incubation at room temperature, the bound phages were eluted, amplified in the host strain and purified by precipitation. A further two rounds of biopanning were carried out in the same way, except that 1:200 and 1:400 sera dilutions were added to $100 \mu \mathrm{l}$ of the diluted phages from the previous round. The percentage of enrichment was calculated using the following formula: percentage enrichment of phage clones $(\%)=$ (eluted phages/added phages) x $100 \%$.

Phage enzyme-linked immunosorbent assay (ELISA). A $10 \mu 1$ volume of eluted phages, from the third round of biopanning, was added to $200 \mu \mathrm{l}$ of the host strain that had been 
Table I. Baseline characteristics of the discovery cohort of patients with chronic hepatitis B, with or without hepatitis B surface antigen seroclearance, following pegylated interferon- $\alpha$ therapy.

\begin{tabular}{|c|c|c|c|c|}
\hline \multirow[b]{2}{*}{ Characteristics } & \multicolumn{2}{|c|}{ HBsAg clearance $(n=30)$} & \multicolumn{2}{|c|}{ HBsAg non-clearance $(n=30)$} \\
\hline & $\operatorname{HBeAg}(+)(n=15)$ & $\operatorname{HBeAg}(-)(n=15)$ & $\operatorname{HBeAg}(+)(n=15)$ & $\operatorname{HBeAg}(-)(n=15)$ \\
\hline Age (years) & $36.2 \pm 9.5$ & $39.6 \pm 10.1$ & $36.2 \pm 9.5$ & $39.6 \pm 10.1$ \\
\hline Number of males (\%) & $8(53.3)$ & $9(60.0)$ & $8(53.3)$ & $9(60.0)$ \\
\hline $\operatorname{BMI}\left(\mathrm{kg} / \mathrm{m}^{2}\right)$ & $19.1 \pm 4.5$ & $18.7 \pm 4.2$ & $18.9 \pm 4.9$ & $18.5 \pm 4.4$ \\
\hline Serum ALT (U/l) & $201.3 \pm 70.6$ & $187.9 \pm 67.5$ & $212.8 \pm 65.0$ & $190.6 \pm 69.2$ \\
\hline HBV DNA ( $\log _{10}$ copies/ml) & $5.8 \pm 0.9$ & $5.6 \pm 0.8$ & $5.9 \pm 0.8$ & $5.7 \pm 0.9$ \\
\hline Serum HBsAg (IU/ml) & $6420.4 \pm 2977.6$ & $5495.7 \pm 2602.5$ & $6119.8 \pm 2412.9$ & $5612.2 \pm 2920.3$ \\
\hline Genotype (B/C/B+C/other) & $3 / 10 / 1 / 1$ & $4 / 9 / 2 / 0$ & $3 / 10 / 1 / 1$ & $4 / 9 / 2 / 0$ \\
\hline
\end{tabular}

The discovery cohort was used to screen for potential serum peptide biomarkers in patients with chronic hepatitis B with HBsAg seroclearance, following pegylated interferon- $\alpha$ therapy. All continuous variables are expressed as the means \pm standard deviation. BMI, body mass index; ALT, alanine aminotransferase; HBV, hepatitis B virus; $\mathrm{HBeAg}$, hepatitis B e antigen; HBsAg, hepatitis B surface antigen.

Table II. Baseline characteristics of the validation cohort of patients with chronic hepatitis B, with or without hepatitis B surface antigen seroclearance, following pegylated interferon- $\alpha$ therapy.

\begin{tabular}{|c|c|c|c|c|}
\hline \multirow[b]{2}{*}{ Characteristics } & \multicolumn{2}{|c|}{ HBsAg clearance $(n=50)$} & \multicolumn{2}{|c|}{ HBsAg non-clearance $(n=50)$} \\
\hline & $\operatorname{HBeAg}(+)(n=31)$ & $\operatorname{HBeAg}(-)(n=19)$ & $\operatorname{HBeAg}(+)(n=28)$ & $\operatorname{HBeAg}(-)(n=22)$ \\
\hline Age (years) & $37.6 \pm 8.9$ & $39.3 \pm 9.7$ & $36.4 \pm 9.2$ & $38.7 \pm 9.5$ \\
\hline Number of males (\%) & $18(58.1)$ & $11(57.9)$ & $18(64.3)$ & $12(54.5)$ \\
\hline $\operatorname{BMI}\left(\mathrm{kg} / \mathrm{m}^{2}\right)$ & $19.5 \pm 4.2$ & $18.9 \pm 4.1$ & $18.8 \pm 4.6$ & $18.6 \pm 4.2$ \\
\hline Serum ALT (U/l) & $194.0 \pm 64.5$ & $191.2 \pm 62.6$ & $201.3 \pm 63.1$ & $185.9 \pm 70.8$ \\
\hline HBV DNA ( $\log _{10}$ copies/ml) & $6.0 \pm 1.0$ & $5.7 \pm 0.8$ & $5.9 \pm 0.7$ & $5.8 \pm 0.8$ \\
\hline Serum HBsAg (IU/ml) & $6935.4 \pm 3086.9$ & $5885.5 \pm 2713.5$ & $6502.6 \pm 2501.3$ & $5939.7 \pm 2985.0$ \\
\hline Genotype (B/C/B+C/other) & $7 / 22 / 2 / 0$ & $5 / 11 / 2 / 1$ & $6 / 19 / 3 / 0$ & $7 / 13 / 2 / 0$ \\
\hline
\end{tabular}

The validation cohort was used for validation of the potential serum peptide biomarker identified in the discovery cohort. All continuous variables are expressed as the means \pm standard deviation. BMI, body mass index; ALT, alanine aminotransferase; HBV, hepatitis B virus; $\mathrm{HBeAg}$, hepatitis B e antigen; HBsAg, hepatitis B surface antigen.

cultured overnight and then incubated for 20 minutes at $37^{\circ} \mathrm{C}$. The transformed host strain cells were then transferred to a culture tube with agarose, quickly vortexed and immediately poured onto a pre-warmed lysogeny broth plate, and incubated overnight at $37^{\circ} \mathrm{C}$. A random selection of 20 phage clones were picked the following day. The ELISA wells were coated with $2 \times 10^{11}$ phage particles and then blocked with $2 \%$ bovine serum albumin (BSA; Sigma-Aldrich, St Louis, MO, USA) in phosphate-buffered saline (PBS). Following blocking, $100 \mu \mathrm{l}$ of a 1:100 dilution of purified sera $\mathrm{IgG}$, from the patients with CHB with HBsAg seroclearance following peg-IFN- $\alpha$ therapy, was subsequently added to the wells, which were incubate for 1 hour at $37^{\circ} \mathrm{C}$. The wells were then washed three times with PBS containing $0.05 \%$ Tween ${ }^{\circledR} 20$. Horseradish peroxidase (HRP)-conjugated goat anti-human IgG antibody (Jackson ImmunoResearch Laboratories, West Grove, PA, USA) was added to the plate, and the specifically bound antibodies were visualized using 3,3',5,5'-tetramethylbenzidine (TMB; Sigma-Aldrich). The absorbance value was measured at $450 \mathrm{~nm}$. The original phage library was used as the negative control and phage clones were considered positive when their absorbance value was $>2$ that of the negative control.

Phage DNA sequencing. The phage clones considered to be positive in the phage-ELISA were precipitated with polyethanol glycol/ $\mathrm{NaCl}$. The phage DNA was then extracted for sequencing using a QIAprep Spin M13 kit (Qiagen) and sequenced with an ABI PRISM 377 sequencer, using the -96 g111 sequencing primer (5'-CCC TCA TAG TTA GCG TAA CG-3')from the Phage Display Peptide Library kit (New England Biolabs, Ipswich, MA, USA).

Determination of the optimal reaction concentration. In order to determine the optimal reaction concentrations, a chessboard titration was performed with the diluted positive phage clones $\left(10^{10} \mathrm{pfu} /\right.$ well, $10^{11} \mathrm{pfu} /$ well, $10^{12} \mathrm{pfu} /$ well, $10^{13} \mathrm{pfu} /$ well and $10^{14} \mathrm{pfu} /$ well) and purified sera $\mathrm{IgG}$ from the patients with CHB with HBsAg seroclearance following peg-IFN- $\alpha$ therapy 
Table III. Phage clone enrichment.

\begin{tabular}{lccc}
\hline Biopanning & Phages Added $(\mathrm{pfu} / \mathrm{ml})$ & Phages Eluted $(\mathrm{pfu} / \mathrm{ml})$ & Enrichment $(\%)^{\mathrm{a}}$ \\
\hline 1 & $6.2 \times 10^{11}$ & $1.6 \times 10^{5}$ & $2.6 \times 10^{-5}$ \\
2 & $3.1 \times 10^{12}$ & $2.2 \times 10^{8}$ & $7.1 \times 10^{-3}$ \\
3 & $1.4 \times 10^{11}$ & $3.0 \times 10^{7}$ & $2.1 \times 10^{-2}$ \\
\hline
\end{tabular}

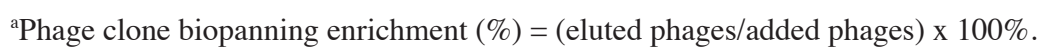

$(1: 10,1: 100,1: 200,1: 400,1: 800)$. The plates were coated with $100 \mu 1$ of diluted phages overnight at $4^{\circ} \mathrm{C}$, and then washed and blocked with $2 \%$ BSA. The sera IgG dilutions were subsequently added and incubated for 1 hour at $37^{\circ} \mathrm{C}$. After incubation with a HRP-conjugated goat anti-human IgG antibody for $1 \mathrm{~h}$ at $37^{\circ} \mathrm{C}$, TMB was added to each well, and the enzymatic reaction was allowed to proceed for 15 minutes at room temperature. The absorbance values were measured at $450 \mathrm{~nm}$, using a microplate reader (BioTek, Beijing, China). The original phage library and the undiluted purified sera $\mathrm{IgG}$ from the patients with $\mathrm{CHB}$ with HBsAg seroclearance following peg-IFN- $\alpha$ therapy, were used as the negative and the positive controls, respectively. Each dilution was repeated in triplicate.

Predictive validity of the positive peptide phage clone. To evaluate the predictive validity of the IFNC1 peptide phage clone, sera from 50 patients with CHB with HBsAg seroclearance and 50 patients with $\mathrm{CHB}$ without $\mathrm{HBsAg}$ seroclearance, following peg-IFN- $\alpha$ therapy, and 50 healthy volunteers were used to react with the IFNC1 clone using a phage-ELISA method. The ELISA wells were coated with $10^{11} \mathrm{pfu} /$ well phage particles and incubated with 1:200 diluted sera IgG. Following the incubation, a 1:2,000 dilution of HRP-Staphylococal Protein A (Life Technologies, Carlsbad, CA, USA) was added, and TMB was used as the substrate for coloration. Absorbance values were measured at $450 \mathrm{~nm}$. The original phage library was used as the negative control, and the phage-ELISA results were considered positive when the absorbance value was $>2$ times that of the negative control. Predictive validity indicators were calculated using the following formulae: sensitivity $=$ true positive/(true positive + false negative); specificity $=$ true negative/(true negative + false positive); positive predictive value $(\mathrm{PPV})=$ true positive/(true positive + false positive); negative predictive value $(\mathrm{NPV})=$ true negative/(true negative + false negative); accuracy $=($ true positive + true negative $) /($ true positive + false negative + true negative + false positive).

Statistical analyses. Statistical analyses were performed using SPSS for Windows version 13.0 (SPSS Inc., Chicago, IL, USA). All continuous variables are expressed as the means \pm standard deviation. The comparisons of the means between two groups were performed using Student's t-tests. The comparisons of the means between multiple groups were performed using a one-way analysis of variance, followed by post hoc pairwise comparisons using Tukey's tests. Categorical variables were compared with $\chi^{2}$ tests. A two-tailed $\mathrm{P}<0.05$ was considered to indicate a statistically significant difference.

\section{Results}

The discovery cohort consisted of 30 patients with CHB who exhibited HBsAg seroclearance following peg-IFN- $\alpha$ therapy and 30 age-, gender-, $\mathrm{HBeAg}$ status- and HBV genotype-matched patients with $\mathrm{CHB}$ without HBsAg seroclearance following peg-IFN- $\alpha$ therapy. Each of the two cohorts contained equal numbers $(\mathrm{n}=15)$ of $\mathrm{HBeAg}(+)$ and $\mathrm{HBeAg}(-)$ patients. As shown in Table I, there were no significant differences in the age, gender, body mass index (BMI), serum ALT level, HBV DNA load, serum HBsAg level and HBV genotype between the HBsAg clearance and non-clearance groups at baseline. A further 50 patients with $\mathrm{CHB}$, with $\mathrm{HBsAg}$ seroclearance and 50 randomly selected patients with $\mathrm{CHB}$ without HBsAg seroclearance, following peg-IFN- $\alpha$ therapy, were enrolled as a validation cohort, to validate the potential serum peptide biomarkers identified in the discovery cohort. In the validation cohort, there were also no significant differences in the baseline characteristics between the HBsAg clearance and non-clearance groups, either in total or by the $\mathrm{HBeAg}(+) /(-)$ subgroups (Table II). In the validation phase, 50 randomly selected healthy volunteers were also enrolled as a control group, which had no significant differences in age (37.9 \pm 8.5 years) and gender (male, $n=31 ; 62 \%$ ), as compared with the HBsAg clearance and non-clearance groups.

As shown in Table III, the percentage enrichment of phage increased from $2.6 \times 10^{-5} \%$ to $2.1 \times 10^{-2} \%$ following three rounds of biopanning, an enrichment of $\sim 1,000$ folds. Purified sera $\mathrm{IgG}$ from the HBsAg clearance group at baseline (within 72 hours before peg-IFN- $\alpha$ therapy), had a positive reaction with 17/20 randomly picked phage clones (85\%; Fig. 1A). The single-stranded DNA from the positive phage clones was then sequenced. Out of the 17 positive phage clones, 13 clones (C1-4, $6,8-9,11-13,15-16,20$ ) had the same inserted DNA sequence 5'-GAA ACC TGT CGT GCC AGC TGC ATT AAT GAA TCG GCC-3' (Fig. 1B). The corresponding peptide sequence was ETCRASCINESA (named IFNC1). Using NCBI Blast software (National Institutes of Health, Bethesda, MA, USA), the identified peptide sequence was searched for in numerous protein databases, including Swissprot (www.ebi.ac.uk/uinprot) and the Protein Data Bank (www.rcsb.org/pdb/home/home.do). No significant homology was determined with other protein sequences (score <50). A chessboard titration was performed to determine the optimal reaction concentrations for the IFNC1 peptide phage clone and sera $\operatorname{IgG}$ from the $\mathrm{HBsAg}$ clearance group. The optimal coating concentration of the IFNC1 peptide phage clone was $10^{11} \mathrm{pfu} /$ well and the optimal dilution for sera IgG from the HBsAg clearance group was 1:200. 
Table IV. Phage-ELISA detection of binding between the IFNC1 peptide phage clone and sera immunoglobulin $\mathrm{G}$ from the healthy controls, and the validation cohorts of patients with chronic hepatitis B, with or without hepatitis B surface antigen seroclearance, following pegylated interferon- $\alpha$ therapy.

\begin{tabular}{|c|c|c|c|c|}
\hline Experimental group & Total number & Absorbance value & Positive number & Positive rate $(\%)$ \\
\hline \multicolumn{5}{|c|}{ HBsAg clearance $(n=50)$} \\
\hline $\operatorname{HBeAg}(+)$ & 31 & $0.942 \pm 0.239^{\mathrm{a}, \mathrm{b}, \mathrm{c}}$ & 29 & $93.5^{\mathrm{a}, \mathrm{b}, \mathrm{c}}$ \\
\hline $\operatorname{HBeAg}(-)$ & 19 & $0.920 \pm 0.245^{\mathrm{a}, \mathrm{b}, \mathrm{c}}$ & 17 & $89.5^{\mathrm{a}, \mathrm{b}, \mathrm{c}}$ \\
\hline Total & 50 & $0.934 \pm 0.241^{\mathrm{a}, \mathrm{d}}$ & 46 & $92.0^{\mathrm{a}, \mathrm{d}}$ \\
\hline \multicolumn{5}{|c|}{ HBsAg non-clearance $(n=50)$} \\
\hline $\operatorname{HBeAg}(+)$ & 28 & $0.397 \pm 0.193^{\mathrm{a}}$ & 3 & 10.7 \\
\hline $\operatorname{HBeAg}(-)$ & 22 & $0.376 \pm 0.181^{\mathrm{a}}$ & 3 & 13.6 \\
\hline Total & 50 & $0.388 \pm 0.189^{\mathrm{a}}$ & 6 & 12.0 \\
\hline Healthy control & 50 & $0.274 \pm 0.108$ & 4 & 8.0 \\
\hline
\end{tabular}

All continuous variables were expressed as the means \pm standard deviation. The comparisons of the means among the multiple groups were performed using a one-way analysis of variance, followed by post hoc pairwise comparisons using Tukey's tests. Categorical variables were compared with $\chi^{2}$ tests. HBV, hepatitis B virus; $\mathrm{HBeAg}$, hepatitis B e antigen; HBsAg, hepatitis B surface antigen. ${ }^{\text {a }}<0.05$ vs. Healthy control; ${ }^{\mathrm{b}} \mathrm{P}<0.05$ vs. IFN-HBsAg non-clearance $\mathrm{HBeAg}(+)$; ${ }^{\mathrm{c}} \mathrm{P}<0.05$ vs. IFN-HBsAg non-clearance HBeAg (-); ${ }^{\mathrm{P}}<0.05$ vs. IFN-HBs Ag non-clearance total.

Table V. Predictive validity of the IFNC1 phage clone.

\begin{tabular}{lccccc}
\hline Control group & Sensitivity $(\%)$ & Specificity (\%) & PPV (\%) & NPV $(\%)$ & Accuracy $(\%)$ \\
\hline HBsAg non-clearance $(\mathrm{n}=50)$ & & & & & \\
HBeAg $(+)(n=28)$ & 92.0 & 89.3 & 93.9 & 86.2 & 82.6 \\
HBeAg $(-)(n=22)$ & 92.0 & 86.4 & 93.9 & 91.7 & 90.3 \\
Total & 92.0 & 88.0 & 88.5 & 92.0 & 92.0 \\
Healthy control $(\mathrm{n}=50)$ & 92.0 & 92.0 & 92.0 & & 90 \\
\hline
\end{tabular}

All indicator values are expressed as a percentage: sensitivity $=$ true positive/(true positive + false negative); specificity $=$ true negative $/($ true negative + false positive); positive predictive value $(\mathrm{PPV})=$ true positive/(true positive + false positive); negative predictive value $(\mathrm{NPV})=$ true negative $/$ (true negative + false negative); accuracy $=($ true positive + true negative $) /($ true positive + false negative + true negative + false positive). HBV, hepatitis B virus; HBeAg, hepatitis B e antigen; HBsAg, hepatitis B surface antigen.

To evaluate the predictive validity of IFNC1, sera from the validation cohort at baseline and the healthy control group were used to react with the IFNC1 peptide phage clone using a phage-ELISA. The original phage library was used as a negative control. As shown in Table VI, sera from 46/50 patients with $\mathrm{CHB}$ with $\mathrm{HBsAg}$ seroclearance and $6 / 50$ patients with $\mathrm{CHB}$ without $\mathrm{HBsAg}$ seroclearance, following peg-IFN- $\alpha$ therapy, and 4/50 healthy controls exhibited a positive reaction with IFNC1. The mean absorbance value of the HBsAg seroclearance group was significantly higher, as compared with the HBsAg non-clearance and healthy control groups, either in total or by the $\mathrm{HBeAg}(+) /(-)$ subgroups. The positive reaction rate of the IFNC1 peptide phage clone was $92.0 \%$ with the HBsAg seroclearance group. This was significantly higher as compared with the HBsAg non-clearance group (12.0\%) and the healthy control group $(8.0 \%)$.

As shown in Table $\mathrm{V}$, the sensitivity of the IFNC1 peptide phage clone to detect patients with $\mathrm{CHB}$ with $\mathrm{HBsAg}$ seroclearance, following peg-IFN- $\alpha$ therapy, was $92.0 \%$, specificity $86.4 \%$, PPV $88.5 \%$, NPV $91.7 \%$ and accuracy $90.0 \%$, as compared with the non-clearance group. As compared with the healthy control group, the IFNC1 peptide had a sensitivity of $92.0 \%$, specificity $92.0 \%$, PPV $92.0 \%$, NPV $92.0 \%$ and accuracy $92.0 \%$, in detecting the patients with CHB with $\mathrm{HBsAg}$ seroclearance, following peg-IFN- $\alpha$ therapy.

\section{Discussion}

Hepatitis B is a potentially life-threatening, infectious liver disease caused by HBV. Worldwide, $\sim 2$ billion people have been infected with $\mathrm{HBV}$, and >240 million have chronic liver infection (11). The covalently closed circular DNA (cccDNA) template of HBV transcription has a key role in the life cycle of the virus and promotes the persistence of infection. It has previously been suggested that the amount of circulating HBsAg reflects the concentration of cccDNA in the liver and therefore the number of infected hepatocytes (4). The aim of CHB antiviral therapy is to clear the cccDNA from the liver. Two treatment strategies may be used, either immune-mediated control, obtained with 48 weeks of peg-IFN therapy; or viral 
A

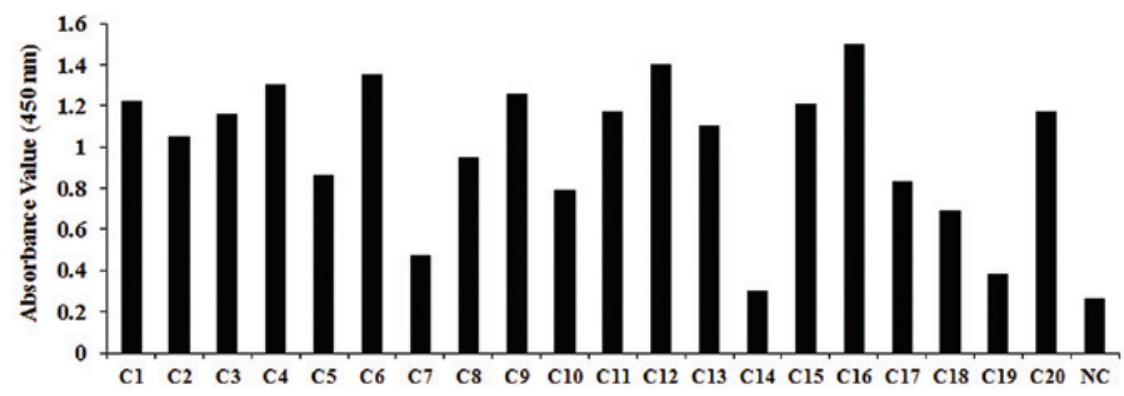

B

GAAAC CTGTC GTGCCAGC TGCATTAATGA ATCGGCC

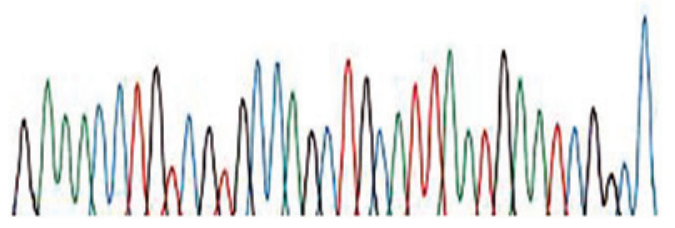

Figure 1. (A) Detection of positive peptide phage clones using phage-ELISA. After three rounds of biopanning, 20 peptide phage clones were randomly selected and reacted with sera from chronic hepatitis B patients,with hepatitis B surface antigen (HBsAg) clearance, following pegylated interferon- $\alpha$ therapy. The phage clones were considered positive when their absorbance values, in a phage-ELISA, were above the cutoff value, which was set to two times of the absorbance value of the negative control value, measured at $450 \mathrm{~nm}$. C1-C20, randomly picked peptide phage clones; NC, negative control (the original phage library). (B) Inserted DNA sequence in the positive peptide phage clones. C1, C2, C3, C4, C6, C8, C9, C11, C12, C13, C15, C16 and C20 positive phage clones had the same inserted DNA sequence 5'-GAA ACC TGT CGT GCC AGC TGC ATT AAT GAA TCG GCC-3'.

control, obtained with long-term nucleoti(si)de analogues, which are potent HBV inhibitors (4). One of the advantages of peg-IFN is that a finite course of therapy may potentially lead to sustained disease remission in subsequent decades (4). HBsAg seroclearance can reportedly be achieved in some patients with hepatitis B in response to peg-IFN- $\alpha$ treatment (2). In the present study, a mimic peptide was identified with a predictive value in differentiating patients with $\mathrm{CHB}$ with or without HBsAg seroclearance, following peg-IFN- $\alpha$ therapy. This was determined using a random phage display peptide library and sera from the patients with CHB prior to peg-IFN- $\alpha$ therapy.

In the discovery/screening phase, the HBsAg clearance group $(n=30)$ was matched with the HBsAg non-clearance group in age, gender, $\mathrm{HBeAg}(+) /(-)$ status, and HBV genotype, in order to minimize background noise for the screening tests. In the validation phase however, patients in the HBsAg non-clearance group $(n=50)$ were randomly selected, therefore the predictive validity of the IFNC1 peptide could be determined in a more realistic context. In the present study, the predominant $\mathrm{HBV}$ genotypes were $\mathrm{B}$ and $\mathrm{C}$, this is in agreement with previous reports that genotypes $\mathrm{B}$ and $\mathrm{C}$ circulate in China $(2,12)$.

The phage display peptide library technique was originally developed to map epitope-binding sites of antibodies, by panning random peptide-phage libraries on immobilized immunoglobulins $(6,7)$. This technique involves specific screening and affinity selection of phages displaying peptides which may be ligands for particular proteins. A major advantage of the technique is the extensive control that may be exerted over the selection conditions, allowing the preservation of the three-dimensional structure of the peptide $(13,14)$. The IFNC1 mimic peptide identified in the present study demonstrated high predictive validity in differentiating patients with $\mathrm{CHB}$ with or without HBsAg seroclearance, following peg-IFN- $\alpha$ therapy, as well as from healthy controls. Therefore, the IFNC1 mimic peptide may be a potential serum biomarker which could be used to predict the therapeutic outcome of peg-IFN- $\alpha$ and to guide the treatment choices for patients with CHB. This may be of particular use for HBeAg (-) patients, whose response rate to peg-IFN therapy is known to be low $(<20 \%)(15)$. Since the IFNC1 mimic peptide exhibited no significant homology with any other protein sequences, it is likely to be derived from an unknown protein. Exploration into the identity and functional roles of IFNC1, and its parent protein(s), may provide novel insights into the molecular mechanisms underlying CHB pathogenesis.

There are some limitations to the present study; in China, patients with CHB have a high chance of co-infection with HCV $(9,16,17)$. However, patients with CHB co-infected with either HAV, HCV, HEV or HIV were excluded from the present study to minimize background noise for the screening tests. Patients with CHB with a comprehensive disease background may be enrolled in future studies, to test the clinical application value of IFNC1. Additionally, only Han Chinese patients with CHB were enrolled in the present study, which minimized the background noise for the screening tests, however it may have limited the validity of the findings. Therefore, it may be interesting to test the predictive validity of IFNC1, or screen for its counterparts, in different ethnicities in future studies.

In conclusion, the IFNC1 mimic peptide was identified as being capable of differentiating between patients with CHB with or without HBsAg clearance, following peg-IFN- $\alpha$ 
therapy. IFNC1 showed high predictive validity for patients with $\mathrm{CHB}$ with $\mathrm{HBsAg}$ clearance, and therefore may be a potential serum biomarker to predict the treatment outcome of peg-IFN- $\alpha$ therapy and to guide the treatment choices for patients with $\mathrm{CHB}$. In addition, the IFNC1 mimic peptide may provide a new basis for exploration into the molecular mechanisms underlying $\mathrm{CHB}$ pathogenesis.

\section{References}

1. Liaw YF and Chu CM: Hepatitis B virus infection. Lancet 373: 582-592, 2009

2. Dusheiko G: Treatment of $\mathrm{HBeAg}$ positive chronic hepatitis B: interferon or nucleoside analogues. Liver Int 33: 137-150, 2013.

3. Blumberg BS, Alter HJ and Visnich S: A "new" antigen in leukemia sera. JAMA 191: 541-546, 1965.

4. Martinot-Peignoux M, Lapalus M, Asselah T and Marcellin P. HBsAg quantification: useful for monitoring natural history and treatment outcome. Liver Int 34: 97-107, 2014.

5. Smith GP: Filamentous fusion phage: novel expression vectors that display cloned antigens on the virion surface. Science 228 $1315-1317,1985$.

6. Samoylova TI, Morrison NE, Globa LP and Cox NR: Peptide phage display: opportunities for development of personalized anti-cancer strategies. Anticancer Agents Med Chem 6: 9-17, 2006.

7. Sergeeva A, Kolonin MG, Molldrem JJ, Pasqualini R and Arap W: Display technologies: application for the discovery of drug and gene delivery agents. Adv Drug Deliv Rev 58: 1622-1654, 2006.
8. Liaw YF, Leung N, Kao JH, et al: Asian-Pacific consensus statement on the management of chronic hepatitis B: a 2008 update. Hepatol Int 2: 263-283, 2008.

9. Zhang Z, Xu L and Wang Z: Screening serum biomarkers for early primary hepatocellular carcinoma using a phage display technique. J Clin Lab Anal 25: 402-408, 2011.

10. Wang M, Yi XY, Li XP, Zhou DM, Larry M and Zeng XF: Phage displaying peptides mimic schistosoma antigenic epitopes selected by rat natural antibodies and protective immunity induced by their immunization in mice. World J Gastroenterol 11: 2960-2966, 2005.

11. Wang Y, Zhao C, Zhang L, et al: Predictive value of interferon-gamma inducible protein $10 \mathrm{kD}$ for hepatitis $\mathrm{B}$ e antigen clearance and hepatitis B surface antigen decline during pegylated interferon alpha therapy in chronic hepatitis B patients. Antiviral Res 103: 51-59, 2014.

12. Tanwar S and Dusheiko G: Is there any value to hepatitis B virus genotype analysis? Curr Gastroenterol Rep 14: 37-46, 2012.

13. Goffinet M, Chinestra P, Lajoie-Mazenc I, Medale-Giamarchi C, Favre G and Faye JC: Identification of a GTP-bound Rho specific $\mathrm{scF}$ v molecular sensor by phage display selection. BMC Biotechnol 8: 34, 2008

14. Nizak C, Monier S, del Nery E, Moutel S, Goud B and Perez F: Recombinant antibodies to the small GTPase Rab6 as conformation sensors. Science 300: 984-987, 2003.

15. Hadziyannis SJ: Treatment paradigms on hepatitis B e antigen-negative chronic hepatitis B patients. Expert Opin Investig Drugs 16: 777-786, 2007.

16. Merican I, Guan R, Amarapuka D, et al: Chronic hepatitis B virus infection in Asian countries. J Gastroenterol Hepatol 15: 1356-1361, 2000

17. Sievert W, Altraif I, Razavi HA, et al: A systematic review of hepatitis $C$ virus epidemiology in Asia, Australia and Egypt. Liver Int 31 (Suppl 2): 61-80, 2011 